\title{
Co-innovation toolbox for demand-supply chain synchronisation
}

\author{
Erno Salmela and Janne Huiskonen \\ Department of Industrial Engineering and Management, \\ LUT University, Lappeenranta, Finland
}

\begin{abstract}
Purpose - The purpose of this paper is to promote decision-making structures between the customer and the supplier in a highly uncertain environment. This phenomenon of demand-supply chain synchronisation includes sharing of high-quality and timely demand and supply information in order to improve the quality and speed of decision-making.

Design/methodology/approach - The study was carried out as an abductive case study, which started from empirical observations that did not match the prior theoretical framework. Through abductive reasoning and empirical experiments, the prior framework was extended to a new synchronisation model and tools that better accommodate the observed need.

Findings - A new co-innovation toolbox was developed to create common understanding of demand-supply chain synchronisation between the customer and the supplier. The toolbox includes Demand Visibility Point-Demand Penetration Point, Supply Visibility Point-Supply Penetration Point and Integrative Synchronisation tools.

Research limitations/implications - The study extends the current models and tools of demand-supply chain synchronisation. With the new toolbox, the development needs of decision-making structures can be identified more comprehensively than with the current tools.

Practical implications - The developed visual toolbox helps partners create a common understanding of problems and development possibilities in demand-supply chain synchronisation in a highly uncertain environment. Common understanding is a starting point for changing decision-making structures to improve the overall performance of a demand-supply chain.
\end{abstract}

Originality/value - The new toolbox is both more comprehensive and more detailed than the previous tools. Keywords Uncertainty, Supply chain coordination, Shared decision-making, Co-innovation, Information quality, Demand-supply chain synchronisation

Paper type Research paper

\section{Introduction}

The study began from a practical need for knowledge about the synchronisation of a demand-supply chain in an uncertain environment between customers and subcontractors in the Finnish high-tech industry. The study focussed on products which were in a growth phase in their lifecycle, making their demand unpredictable. The uncertainty focussed particularly on the amount of material. The subcontractors needed earlier demand information from their customers, and the customers earlier supply information from their subcontractors, to make their decisions sooner. Because of the lateness of demand information, the subcontractors had challenges in responding cost-effectively to the demand changes of their customers. On the other hand, because of the lateness or lack of supply information, the customers were unable to anticipate supply disruptions.

It is generally known that suppliers face the challenge of creating cost-effective responses to market demand under uncertain circumstances (Kafi and Kafi, 2016; Wiengarten et al., 2010;

C Erno Salmela and Janne Huiskonen. Published by Emerald Publishing Limited. This article is published under the Creative Commons Attribution (CC BY 4.0) licence. Anyone may reproduce, distribute, translate and create derivative works of this article (for both commercial and non-commercial purposes), subject to full attribution to the original publication and authors. The full terms of this licence may be seen at $\mathrm{http}: / /$ creativecommons.org/licences/by/4.0/legalcode
Demand-supply chain

synchronisation

Received 5 September 2018 Revised 18 January 2019 15 February 2019 Accepted 2 March 2019 
IJOPM

39,4

Affonso et al., 2008). Respectively, customers are faced with the challenge of responding cost-effectively to supply disruptions (Fleischmann and Geier, 2012; Li et al., 2006; Barut et al., 2002). The fragmentation of business processes has increased these kinds of challenges when decision-making is dispersed among companies (Wiengarten et al., 2010; Arshinder et al., 2011). Coordination is needed because achieving the objectives of one company depends on the decisions and actions of other companies (Moon and Kim, 2005; Alexander, 1995). Coordination is successful when customers and suppliers make decisions that promote the business of both companies (Eltantawy et al., 2015; Alexander, 1995).

For highlighting the importance of information sharing and decision-making from both directions of the supply chain, two key processes are conceptually separated. Demand chain refers to the demand information process of the customers, and supply chain refers to the material or service flow and the related information from the suppliers (Holmström et al., 1999). Demand chain management aims at understanding the behaviour of customers and markets, managing demand processes and creating new demand, whereas supply chain management focusses on improving the efficiency of the production and logistics processes (Langabeer and Rose, 2001). As the demand and supply chains affect each other (Walters, 2006), they should be coordinated and information shared in both directions. The combination is called demand-supply chain management (Hoover et al., 2001) with the goal of coordinating the demand creation and fulfilment processes across interorganisational boundaries (Hilletofth, 2011).

The differences in interest between companies and the uncertainty of the operating environment are the foremost drivers for the need to coordinate demand-supply chains (Arshinder et al., 2011; Rojas and Frein, 2008). Contradictory interests and uncertainty lead to companies optimising their own operations and ignoring the effects this has on their partners. Uncertainty is passed on to the partners in order to minimise one's own risks and costs instead of endeavouring to manage uncertainty together (Arun Kanda and Deshmukh, 2008; Rojas and Frein, 2008).

Uncertainty can be derived from mismatches between demand and capacity, and it occurs due to the lack of ability to forecast accurately (Walker et al., 2003). High uncertainty in demand occurs especially in the ramp-up and ramp-down phases of a product's lifecycle (Kaipia and Holmström, 2007). Unexpected fluctuations between the forecasted and actual volume are common (Datta and Christopher, 2011).

Sharing high-quality information in time is an essential means of decreasing uncertainty. Anticipating upcoming orders lowers the costs of buffering, and improves the ability to serve the customer better (Kaipia et al., 2007; Hoover et al., 2001). Therefore, time or speed is an increasingly important competitive factor in an uncertain environment. To reach the same clockspeed among companies, information about changes, exceptions and decisions should be shared quickly to partners (Simatupang and Sridharan, 2008; Li and Wang, 2007; Kaipia, 2007). Thus, the synchronisation of decision-making is closely related to sharing information (Simatupang and Sridharan, 2005). Supply chain performance can be improved by connecting information sharing and decision-making with material flow (Soroor et al., 2009; Kaipia, 2009).

Information sharing and the synchronisation of decision making are coordination mechanisms which help manage interdependencies between processes (Piplani and $\mathrm{Fu}, 2005$; Simatupang et al., 2004), such as demand and supply chains, and information and material flows (Hilletofth, 2011; Holmström et al., 1999). We use the concept of demand-supply chain synchronisation for this phenomenon consisting of information sharing and decision-making synchronisation as coordination mechanisms, which is in line with, e.g., Hietajärvi et al. (2009), Holmström et al. (1999) and Zeng and Pathak (2003). In demand-supply chain synchronisation, the main issue is not information sharing, but the development of decision-making structures between companies (Hietajärvi et al., 2009; Holweg et al., 2005). 
The lack of understanding of supply chain dynamics has hampered the implementation of coordination mechanisms at a practical level (Hilletofth and Lättilä, 2012; Arun Kanda and Deshmukh, 2008). To develop business together, customers and suppliers should create shared knowledge and common understanding of inter-organisational business processes (Lavikka, 2015; Jaatinen and Lavikka, 2008). Partners should discuss, for example, the utilisation of shared information (Baihaqi and Sohal, 2013) with the aim of improving its quality (Li and Wang, 2007).

In the literature, search for demand-supply chain synchronisation, the Value Offering Point-Order Penetration Point (VOP-OPP) (Holmström et al., 1999) seemed the most promising of the tools. It consists of the above-mentioned coordination mechanisms, and aims at overall performance improvement by changing decision-making structures. The timing of information and decision-making plays a crucial role in the VOP-OPP, as well as common understanding between the customer and supplier to move the VOP and OPP simultaneously (Holmström et al., 1999). The selection of this tool for empirical experiments was also supported by the research results of Yuan et al. (2013). They recognised 17 hybridpositioning modes of VOP and OPP in the manufacturing industry, which is an essential subsector of the Finnish high-tech industry.

However, the practical experiment showed that the VOP-OPP did not work properly in the environment of highly uncertain demand and supply. Therefore, the need arose to understand why it did not work and what kind of tools would work better. In consequence, an abductive research process was launched.

In the following, the first experiment of the VOP-OPP tool and its results are presented. Section 3 describes the research methodology. Section 4 includes theory matching in order to create new synchronisation tool proposals, after which the new proposals are presented in Section 5 . Section 6 discusses the results, and Section 7 concludes the study and presents the needs of further research.

\section{Suitability of VOP-OPP to create common understanding in uncertain circumstances}

After defining the practical problem, the researchers searched theoretical knowledge on tools, which help analyse information, material and decision-making flows from the point of information timing. VOP-OPP and its predecessors (e.g. Customer Order Decoupling Point; Hoekstra and Romme, 1992) and derivatives (i.e. Demand Visibility Point (DVP)-Requirements Penetration Point; Holmström et al., 2010) were found. As the predecessors and derivatives did not seem to offer significantly different points of view, the VOP-OPP was chosen as a preliminary framework to help companies create common understanding of the problems in their demand-supply chains.

\section{Value Offering Point - Order Penetration Point}

The VOP-OPP presented by Holmström et al. (1999) models the synchronisation of the demand-supply chain (Figure 1). In their model, the demand and supply chains link together

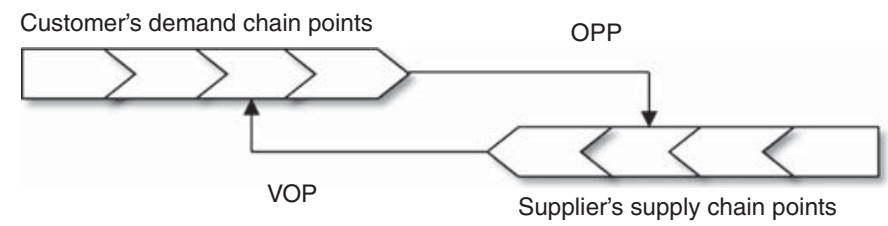

Source: Holmström et al. (1999)

Figure 1. VOP-OPP model 
IJOPM

39,4 at two points - the demand chain's Value Offering Point (VOP) and the supply chain's Order Penetration Point (OPP) (Holmström et al., 1999).

The customer company shares information with the supplier about its own needs at different points of the demand chain. The main points of the demand chain are identified as purchasing, consumption, planning/design and purpose. The VOP is the part of the demand chain where the customer allocates its demand to a certain supplier by placing an order with that supplier (Holmström et al., 1999; Hoover et al., 2001). The order is focussed at the point $(\mathrm{OPP})$ in the supplier's process, where the material is allocated to the customer (Holmström et al., 1999).

The OPP is located in the supply chain at the make-to-stock and make-to-order interface, where the specifications of the order are usually frozen. The further upstream in the supply chain the OPP is located, the longer the material lead-time becomes (Hoover et al., 2001). On the other hand, the earlier the stage at which the VOP is located in the customer's demand chain, the more time the supplier has to respond to the demand (Holmström et al., 1999; Hoover et al., 2001).

The concept of time advantage has been linked to the VOP-OPP model, and it refers to the advantages in costs and/or customer value of the supply chain arising from the previous sharing of demand information. Because of this additional time, the supplier can plan their operations better, and consequently offer better customer service more cost-efficiently (Kaipia, 2007). The supplier can utilise the additional time by moving the OPP in their supply chain further upstream - for example, from the dispatching inventory to the component inventory, and, in this way, reduce storage costs (Hoover et al., 2001).

Holmström et al. (1999) suggest that the customer and supplier can obtain mutual advantages if the VOP and OPP are moved simultaneously. They point out that if only one of the points is moved, usually only one party profits from it. The vendor-managed inventory (VMI) is a good example of the advantages achieved through the simultaneous relocation of the VOP and OPP, as the VMI allows the simultaneous reduction of the supply chain costs and the improvement of the service level (Hoover et al., 2001; Holmström et al., 1999).

The VOP-OPP model has been successfully utilised in various operating environments, e.g. grocery stores, maintenance, mobile network operations, and IT services (Hoover et al., 2001; Collins, 2003; Kaipia, 2007; Kaipia et al., 2007; Yuan et al., 2013).

\section{Experiments of VOP-OPP tool and observations from them}

The VOP-OPP model was experimented in workshops with three Finnish technology industry manufacturer-subcontractor pairs to create a common understanding of demandsupply chain synchronisation problems and find solutions to them.

Based on the workshops and the subsequent interviews, the VOP-OPP model was found to be a suitable tool for an environment of low uncertainty, but in the case of higher uncertainty, it did not work properly. Therefore, the need arose to understand why it did not work and find the explanation for this and adjust the model accordingly.

The VOP-OPP was found to have the following shortcomings:

(1) It focusses only on order as demand information and ignores the pre-order (e.g. forecasts) information and post-order demand information (e.g. changes in orders). On the other hand, the VOP-OPP examines the use of the demand information merely from a material allocation point of view. Demand information can also be utilised in other ways such as reserving capacity.

(2) It ignores entirely the supply information provided by the supplier and the way in which the customer utilises it. Late, or a lack of, supply information is a problem for customer companies, especially if deliveries from subcontractors are late. 
(3) Apart from timing, it does not take into account the quality of the information. At Demand-supply least the reliability and accuracy of information should be noticed.

(4) It does not take into account customer and supplier flexibilities (e.g. additional capacity). synchronisation

In consequence, the earlier criticism of the VOP-OPP was sought from the literature. According to the main criticism, the interaction of only two points (VOP and OPP) is considered a restricted approach when presenting the interaction between demand and supply chains. This means that information can also be shared from points other than VOP, and it could be utilised in different ways, not just in material allocation decisions like in the VOP-OPP. First, it may be useful to paint a broader context by using the notion of the value chain and overall creation of value. An example of this is the synchronisation between sales and production when reconciling sales forecasts with production planning. Second, VOP-OPP emphasises demand-driven processes. Perhaps, there is also need for supply-driven processes. (Rainbird, 2004).

\section{Methodology}

The recognised deficiencies of the VOP-OPP triggered the abductive case study. The study aimed at improving the existing VOP-OPP tool by developing its empirically identified deficiencies to create a refined version of the tool, and experiment it in practice.

Abduction is seen as systematised creativity or intuition to develop new knowledge by breaking out of the already known constructs (Andreewsky and Bourcier, 2000). Intuition often results from an unexpected observation that cannot be explained using an existing theory (Dubois and Gadde, 2002; Andreewsky and Bourcier, 2000).

Abduction builds more on the refinement of existing theories than on inventing new ones (Kovács and Spens, 2005). It works through interpreting existing phenomena within a contextual framework, and aims at understanding something in a new way (Danermark, 2001; Dubois and Gadde, 2002), providing a new explanation for the phenomenon (Ketokivi and Mantere, 2010).

The abductive approach follows the process from a (generic) rule to a (surprising) result to a (new) case (Danermark, 2001). An empirically observable phenomenon is related to an existing rule (theory, model, tool), which gives new insight into the phenomenon.

Figure 2 presents the research process of the abductive approach starting with a real-life observation (Alvesson and Sköldberg, 1994) or prior theoretical knowledge (Kovács and Spens, 2005).

Abductive reasoning starts at the point at which the empirical observations do not match prior theories. After this, theory matching attempts to find a new matching framework or to extend the prior theory (Dubois and Gadde, 2002; Andreewsky and Bourcier, 2000). Empirical data are collected simultaneously with theory building. Emphasis on verification is not the main issue, but revealing new dimensions of the research problem.

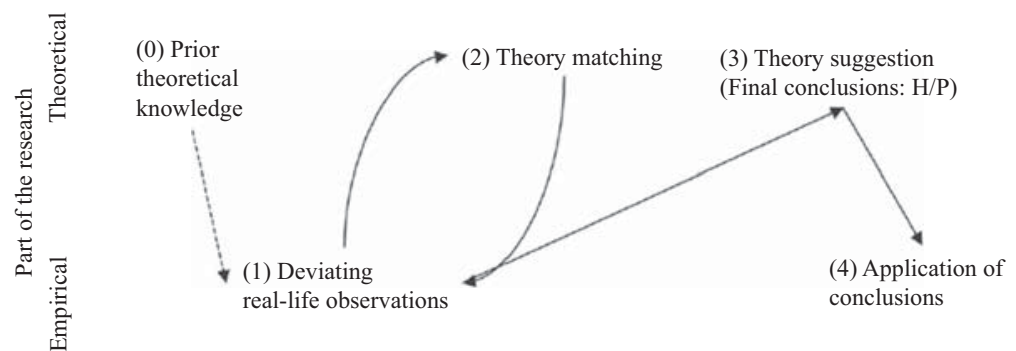

Source: Kovács and Spens (2005)

Figure 2.

Abductive research process 
IJOPM

39,4

Instead of focussing on generalisations, the abductive approach is concerned with the particularities of specific situations deviating from the general structure. The creative-intuitive aspect makes abduction suitable for the first phase of research (Kovács and Spens, 2005; Godsell et al., 2018). The primary aim is to understand the new phenomenon (Alvesson and Sköldberg, 1994) and to suggest new theories in the form of new propositions (Andreewsky and Bourcier, 2000). The deductive part of the research, application of hypotheses, may follow the abduction (Kovács and Spens, 2005).

The interaction between a phenomenon and its context is best understood through in-depth case studies, which provide unique means of developing theory (Dubois and Gadde, 2010, 2002; Weick, 1979). The identification of sub-units, embedded designs, allows for a more detailed level of case study. The embedded case study is suitable for studies where the goal is to describe the context, features and process of a phenomenon. (Yin, 2003; Scholz and Tietje, 2002).

In case studies, analytic generalisation is used instead of statistical one. Analytic generalisation includes two steps: first, a conceptual claim is made to show how findings bear upon a theoretical construct. Second, this theory is applied to implicate situations in which similar events might occur (Yin, 2010).

Literature tends to describe case studies as a linear process consisting of planned subsequent "phases". Instead, by constantly going back and forth between empirical observations and theory, the researcher is able to understand both theory and empirical phenomena. Therefore, abduction approach's theory matching or systematic combining brings non-linearity to "traditional" case study recommended by Yin and Eisenhardt (Dubois and Gadde, 2010, 2002).

Research process

After the practical problem recognition, the study followed the process presented in Figure 2:

(1) The search for prior theoretical knowledge about tools, which help the synchronisation of the demand-supply chain. VOP-OPP and its predecessors and derivatives were found. As the derivatives did not seem to bring significant new aspects to the empirical problem, the VOP-OPP was chosen as a preliminary framework when fieldwork was initiated.

(2) Deviating real-life observations: VOP-OPP was experimented in three customersubcontractor cases to reveal problems in their demand-supply chain synchronisation. At the same time, it was revealed that VOP-OPP was not good enough a tool in an environment of uncertain demand and supply. The deficiencies of VOP-OPP were recorded.

(3) Theory matching: complementary to the VOP-OPP, new theoretical knowledge was searched for the areas missing from the VOP-OPP, and was utilised to create new synchronisation tool propositions for an environment of uncertain demand and supply. After this, embedded designs of new tools were created and experimented through thematic interviews in customer-subcontractor cases to see their functionality and the needs for refining.

(4) Theory suggestion: after the learning loops in the case study of the previous stage, tool propositions were refined. Furthermore, an integration tool was discovered as a new tool proposition. Based on a combination of theoretical and empirical knowledge, the DVP-DPP, Supply Visibility Point-Supply Penetration Point (SVP-SPP) and integrated DVP-DPP and SVP-SPP tools were finally proposed. New tools were experimented in the same manufacturer-subcontractor pairs as in the earlier VOP-OPP tool experiments. In this way, the benefits of the new tools could be estimated compared to the VOP-OPP.

(5) Application of conclusions: the suggested tools were not deductively researched in this study. 
Each studied demand-supply chain contained one manufacturer and one subcontractor. All the companies came from the Finnish high-tech industry. The study focussed on products (e.g. innovative welding, packaging, mining and waste processing machines) that were in a growth phase in their lifecycle, making their demand unpredictable. The studied manufactures were global companies and pioneers in their field. The studied subcontractors were SMEs and operated mainly on the Finnish market. Subcontractors were chosen as the studied supplier group because they usually have the most synchronisation practices with

The manufacturers suggested studying one of their subcontractor networks, the one
The studied subcontractors produced mechanical, hydraulic and electric with the most synchronisation practices with it. On average, the chosen subcontractor covered 90 per cent of all synchronisation practices the manufacturer used with its subcontractors. Proceeding in this manner, it was possible to gain an effectively comprehensive picture of the synchronisation practices of each studied demand-supply chain. From the studied companies, the CEOs and purchasing, production and logistics managers were involved in the research.

The study included two types of demand-supply chain company pairs:

(1) Company pairs who experimented sychronisation tools to analyse their demandsupply chains in workshops: at the beginning of the study, they experimented the VOP-OPP tool. Finally, the same companies experimented the new synchronisation tools. In this way, the differences between the old and new tools could be estimated.

(2) Company pairs who were interviewed to find out how their synchronisation practices match with the new tool propositions: initially, five company pairs were selected. Their synchronisation practices matched with 90 per cent of the different elements of the new tools. Therefore, three more pairs were selected. After this, all the elements were matched - most of them many times in the studied demand-supply chains. In addition, new practices were revealed that were not included in the propositions.

\section{Theory matching - creating and experimenting new synchronisation tool proposals}

The first empirical experiments showed that the VOP-OPP model did not work well in an environment of highly uncertain demand and supply. Since the experiments revealed the major weaknesses of the VOP-OPP, theoretical knowledge was searched for four recognised areas missing from the VOP-OPP. The proposals for the new synchronisation tools were created by combining some of the elements of the predecessors and derivatives of the VOP-OPP found in the literature. After the creation of the new tool proposals, the embedded case designs of the tools were created and experimented in practice to see their functionality and needs for refining.

\section{Creating new synchronisation tool propositions}

Functionality 1 missing from VOP-OPP: pre-and post-order demand information and its utilisation. VOP-OPP concentrates only on order information. Instead, the DVP means the same as the VOP, but it can include other demand information in addition to the order information, e.g. forecasts (Holmström et al., 2010; Collin et al., 2009). However, post-order demand information has not been taken into account in its definition.

Sharing demand information is particularly important when changes are made (Galasso et al., 2009; Kaipia et al., 2007; Hirvonen, 2006). Therefore, post-order information is necessary synchronisation 
IJOPM

39,4
(Galasso et al., 2009; Salmela and Happonen, 2008; Collin, 2003). Based on this, the concept of DVP can be redefined as follows: the DVP is the point in the customer's process, from which the customer shares pre-order and post-order demand information in addition to order information.

In the VOP-OPP, demand information is utilised only at the OPP, where material is allocated to a specific customer. However, suppliers can utilise demand information in more ways than just material allocation decisions, e.g. in reserving capacity and planning production (Salmela et al., 2012; Holmström et al., 2010). Christopher (1998) presents the concept of the Demand Penetration Point (DPP), but it means the same as the OPP.

The DPP would be suitable as a counterpart for the DVP, but it must be redefined as follows: the DPP is the point in the supplier's process where any demand information penetrates, not just order information. In this case, the supplier can make different decisions at its DPP, not just material allocation decisions.

In summary, the concept of Demand Visibility Point-Demand Penetration Point (DVP-DPP) could replace the VOP-OPP in an environment of highly uncertain demand. It includes the sharing of different kind of demand information by the customer (DVPs) used by the supplier in various supply chain decisions (DPPs).

Functionality 2 missing from VOP-OPP: sharing and utilisation of supply information. The VOP-OPP ignores entirely the supply information provided by the supplier and the way in which the customer utilises it, although it is very important to be shared and utilised in an environment of high supply uncertainty (Salmela et al., 2012; Barut et al., 2002). The supply information can be utilised in the customer's decision-making chain in many ways (Fleischmann and Geier, 2012; Li et al., 2006). The earlier the customer receives information, e.g. about delivery disruptions, the more time the customer has to reduce the negative effects of the disruptions (Fleischmann and Geier, 2012; Salmela et al., 2012).

The sharing and utilisation of supply information could be viewed in synchronisation in the same way as demand information by defining the respective concepts SVP-SPP as follows: the SVP is the point in the supplier's process, from which the supplier shares supply information. The SPP is the point in the customer's process where supply information penetrates, and where the customer makes different decisions.

Functionality 3 missing from VOP-OPP: information quality dimensions needed in environments of uncertainty. The VOP-OPP addresses only the timing of information as an information quality dimension. Besides the timing of information, important dimensions also include reliability and accuracy in supply chains with high uncertainty (Baihaqi and Sohal, 2013; Wiengarten et al., 2010; Gustavsson and Wänström, 2009; Kaipia, 2007).

In the DVP-DPP and SVP-SPP, the accuracy and reliability levels of information are also taken into account as information quality dimensions. This means that decisions must often be made based on inaccurate and unreliable information, which affects the quality of the decision (Rojas and Frein, 2008; Kaipia, 2007; Piplani and Fu, 2005). When operating based on low-quality information, it is a matter of taking a risk. The question of who will bear the risk remains (Collin, 2003; Salmela and Happonen, 2010).

In summary, the DVP-DPP and SVP-SPP include timing, accuracy and reliability as information quality dimensions.

Functionality 4 missing from VOP-OPP: customer and supplier flexibilities. The VOP-OPP does not consider customer and supplier flexibility in responding to changes in supply and demand. However, unexpected changes in demand and supply make flexibilities an important part of synchronisation. Flexibility is required when actual demand or supply deviates from the predicted or planned demand or supply. Flexibility refers to the customer's or supplier's ability to respond to changes, e.g. in delivery times or quantities (change in supply) or order volumes (change in demand) (Hopp and Sperman, 2008; Kaipia and Holmström, 2007; Björk, 2006; Pagell and Krause, 2004; Hoover et al., 2001). 
In conditions of high uncertainty, flexibilities should be planned to meet the uncertainties (Wochinger et al., 2013; Bauernhansl et al., 2012; Hoover et al., 2001). Flexibility is usually based on buffers. A buffer is an excess resource correcting misaligned demand and supply. Demand and supply can be balanced through inventory, timing and capacity buffers (Wochinger et al., 2013; Hopp and Sperman, 2008).

When the supplier has high flexibility, the customer should develop their demand information in order to take advantage of the flexibilities to their fullest (Kaipia, 2007; Kaipia and Hartiala, 2006). Similarly, supply information has a significant role in the utilisation of the customer's flexibilities (Salmela et al., 2012; Björk, 2006; Sawhney, 2006). On the other hand, sharing information and flexibilities are partly considered as being the opposites of each other. Good quality information reduces the need for flexibilities (Hirvonen, 2006; Huiskonen, 2004).

In the DVP-DPP and SVP-SPP, customer and supplier flexibilities are taken into account from the perspective of at what time, accuracy and reliability the demand or supply information is needed to get the flexibility in use while being cost-efficient at the same time (e.g. Aslam et al., 2018).

\section{Proposals for new synchronisation tools and their embedded designs}

Based on theory matching, two new synchronisation tool proposals were created. The demand-driven synchronisation proposal was named DVP-DPP, and, respectively, the supply-driven synchronisation proposal was named SVP-SPP. The DVP and the SVP indicate the location in the process from which the customer or supplier share information with their partner. Demand information is divided into three information categories: preorder, order-related and post-order information. The DPP and SPP indicate the location in the process in which the partner utilises the received information in their decision-making. The proposals for the DVP-DPP and SVP-SPP are shown in Figure 3.

(a)

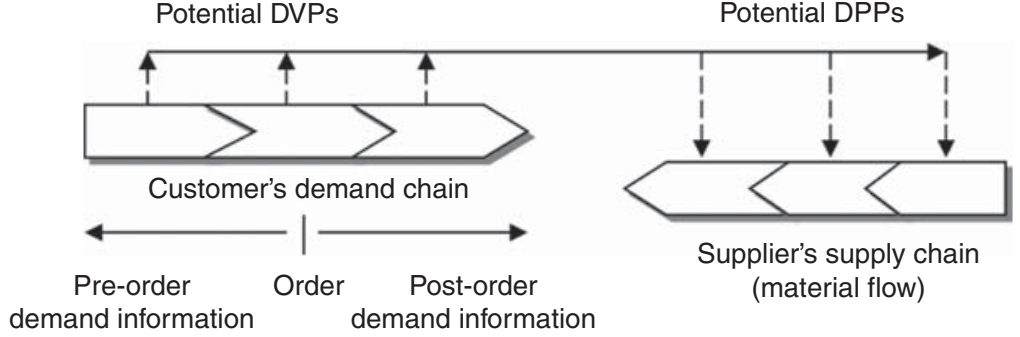

(b)

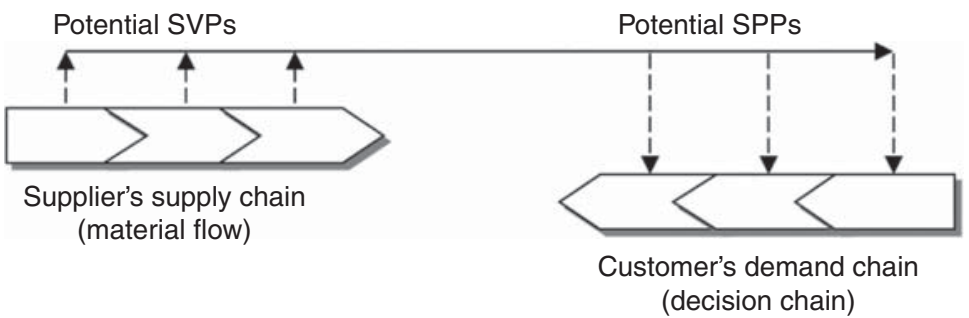

Notes: (a) Proposal of DVP-DPP tool; (b) Proposal of SVP-SPP tool

Figure 3. Proposals for synchronisation tools 
IJOPM

39,4

Table I.

Embedded designs of sychronisation proposals

Since the scope of the DVP-DPP and SVP-SPP makes it difficult to evaluate the functionality of these tools as such in practical demand-supply chains, the proposals were broken down into five embedded designs as logical sub-units (Table I).

\section{Evaluating the empirical functionality of embedded designs}

The objective of this phase was to evaluate how the embedded designs of the DVP-DPP and SVP-SPP function in practical demand-supply chains. The definitions of the embedded designs were used in the thematic interviews when collecting empirical data. At this stage, new insights into their usability were still expected. The proposals would be further developed if the empirical evidence indicated the need for it. The objective was not to verify embedded designs with statistical but analytical generalisation. This means that the theoretical constructs (embedded designs) were applied to practice to recognise situations in which similar events might occur.

The experiments brought up new synchronisation instances, which had not been included in the earlier proposals. The discovered new synchronisation features were added to the DVP-DPP and SVP-SPP proposals.

\section{Theory suggestion - proposals for new synchronisation tools}

Regarding the DVP-DPP tool, a new category was added to demand information: post-delivery date demand information (e.g. expediting of deliveries). The supply chain was divided into material and service flows because these involve different decisions. For example, the reservation of capacity for the sake of flexibility is critical in the service flows, which cannot be buffered by inventories. The principle of the updated DVP-DPP is shown in Figure 4, which also presents the common DVPs and DPPs found in the practical demand-supply chains.

Regarding the SVP-SPP tool, supply information can also be divided into four information categories: pre-order, order-related, post-order and post-delivery date information. On the other hand, the subcontractor's supply chain is divided into material and service flows because they involve different kinds of supply information. The principle of the updated

\section{Embedded designs Descriptions of embedded designs}

Panel a: embedded designs broken down from DVP-DPP proposal

1. Pre-order demand Pre-order demand information can come from the customer's demand chain information and its utilisation planning (including predicting) and consumption (e.g. inventory) Includes the change perspective of demand information (e.g. improved forecasts) Includes a risk-sharing perspective in a situation of low-quality demand information

2. Post-order demand Includes a change perspective of the order information (e.g. more precise specifications) information and its utilisation

3. Synchronisation of Focusses on reconciling demand uncertainly and supplier flexibilities supplier-side flexibilities with Includes not only the planning of flexibilities, but also the perspective of reserving flexibilities, in which case the quality of demand information is taken into account uncertainties in demand

Panel b: embedded designs broken down from SVP-SPP proposal

1. Sharing and utilisation of supply information

2. Synchronisation of customer-aid flexibility with supply uncertainties
Supply information particularly refers to the supplier's change and exception situations which have potential to lead to supply disruptions

Supply information can be shared from the different points of the supplier's delivery process

Focus on reconciling supply uncertainty and customer flexibilities

Includes not only the planning of flexibilities, but also the perspective of sharing supply information, in which case die quality of supply information is taken into account 


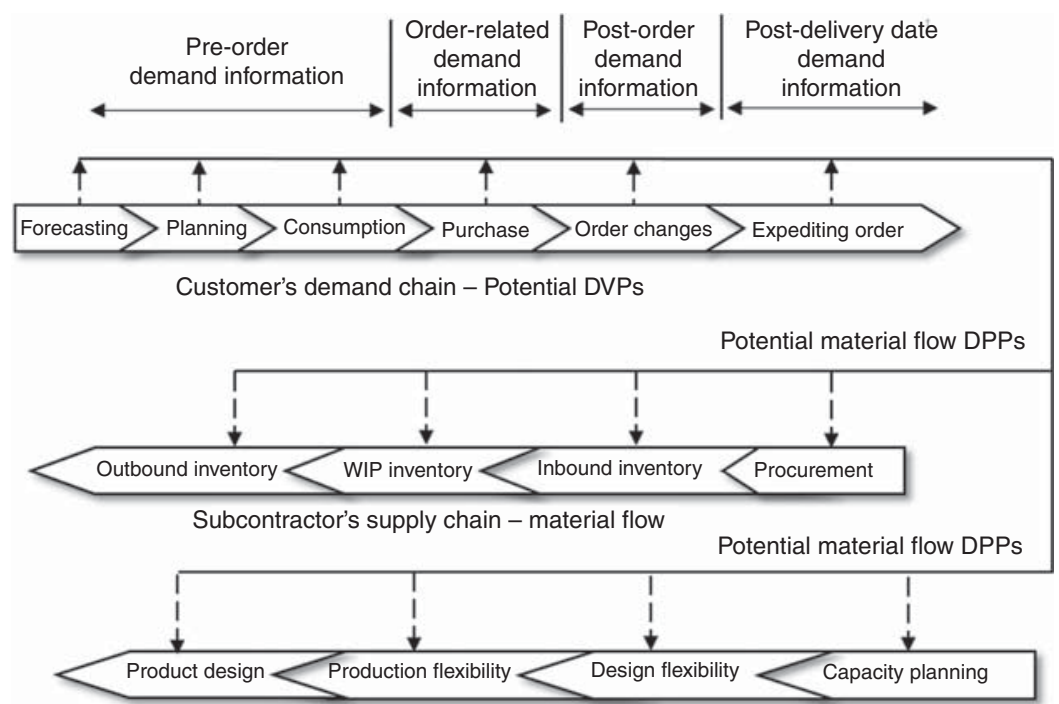

Demand-supply chain

synchronisation

583

Subcontractor's supply chain - service flow

SVP-SPP model is shown in Figure 5, which also includes some common SVPs and SPPs found in the practical demand-supply chains.

\section{Integrated synchronisation tool}

The interviews revealed that, at its best, comprehensive demand-supply chain synchronisation calls for both demand and supply-driven perspectives in an integrated manner (Figure 6).

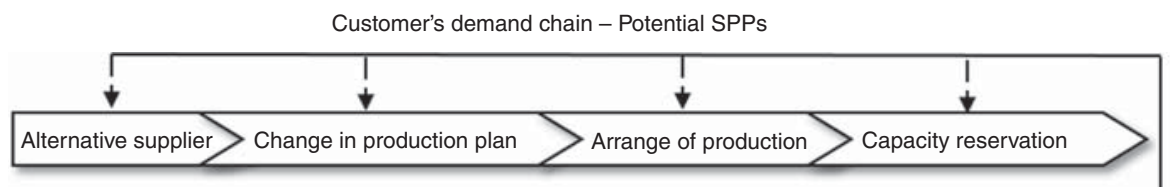

Subcontractor's supply chain - Potential service flow SVPs

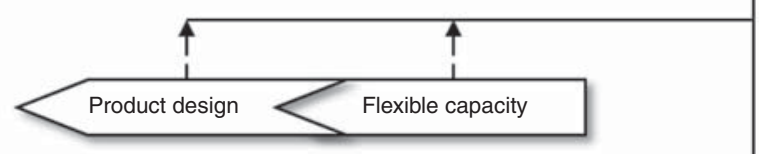

Subcontractor's supply chain - Potential material flow SVPs

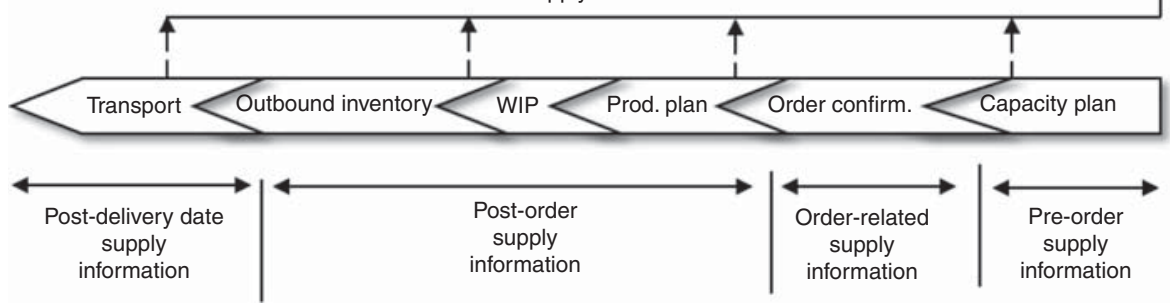

Figure 5.

SVP-SPP tool with SVP and SPP examples 
IJOPM

39,4

584

In other words, the DVP-DPP and SVP-SPP processes are linked to each another. Furthermore, the different information categories (pre-order, order-related, post-order and postdelivery date information) should be taken into account seamlessly and together.

\section{Added value of the new tools}

This section presents practical examples of synchronisation from the perspective of what is the added value of the new tools compared to the VOP-OPP model and its derivatives. The examples present different elements of the DVP-DPP, SVP-SPP and the integrated synchronisation model by taking into account the demand- and supply-driven synchronisation, the four information categories, and the demand- and supply-side flexibilities. An example concerning only order-related demand information is not presented because the VOP-OPP model and its derivatives include this demand information category.

Example 1: pre-order demand information and its utilisation. A manufacturer claimed a shorter delivery time, and therefore its subcontractors had to manufacture tailor-made materials to stock. In this case, the manufacturer's production forecast was used as preorder demand information (DVP). As the manufacturer's forecast was not an order, the subcontractors took on the risk of uncertainty. Some of the subcontractors were frustrated by the manufacturer's forecasting errors and began to make their own forecasts, using the manufacturer's production forecast as one input. Thus, the subcontractors utilised the demand information from the customer in creating their own demand information (DPP) not directly for material flow decisions.

Example 2: post-order demand information and its utilisation. A manufacturer offered its subcontractors visibility to its production progress (DVP) after the orders had been placed. In consequence, the subcontractors could delay (DPP) their deliveries if the manufacturer's production was delayed. However, this approach did not work in practice. The subcontractors' supply disruptions increased. For many subcontractors, managing capacity and lead times was challenging even without changes. In addition, the manufacturer sometimes succeeded in avoiding its anticipated production delay. Thus, its demand information was unreliable.

Example 3: post-delivery date demand information and its utilisation. When subcontractors did not share information about delayed deliveries, the manufacturer had to inquire about the state of delivery and at the same time expedite the subcontractors for quick delivery (DVP). Unbelievable but true, some of their subcontractors scheduled their own production (DPP) based on a list of late materials sent by the manufacturer.

Example 4: synchronisation of supply-side flexibilities with demand uncertainty. A subcontractor had created a service model corresponding to their customers' demand uncertainty. In this model, the manufacturer could order material from the subcontractor faster than the agreed delivery time or for a bigger amount than agreed by paying an

Figure 6.

Integrated synchronisation model

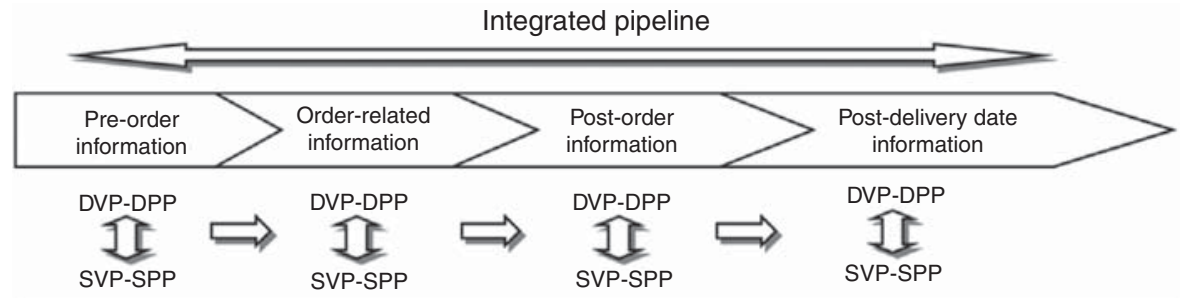

Material flow

Service flow 
additional price. The model called for the required timing and accuracy of demand information when the manufacturer informed about changes in demand (DVP) so that the subcontractor would be able to respond cost-efficiently to the changed demand. Flexibility was not immediately available, but there was an activation delay for different capacity types. This delay was the shortest when the subcontractor used production flexibilities and the longest when it had to hire additional labour (DPP).

The requirement for demand information accuracy meant that, in different time spans, the need for capacity was not required at the same level of accuracy. For example, four weeks before the need of flexibility, work-specific (e.g. machining) capacity needs did not need to be known, but it was enough to estimate the total capacity. When approaching the utilisation of the flexible capacity, the demand information had to be specified as work-specific hourly estimates (DVP). The gradually increasing accuracy requirements of the demand information define the reliability level of the demand information. When a manufacturer does not need to know weeks in advance the accurate work-specific hours, but, for example, only an estimate between 150 and $200 \mathrm{~h}$, the demand information is inherently reliable. This example describes well how the reliability, accuracy and timing of information affect each other.

Example 5: pre-order supply information and its utilisation. As pre-order supply information, some subcontractors informed a manufacturer about planned breaks in production, such as holiday periods, and exceptional situations, such as unexpected production downtimes and capacity overloading (SVPs). The manufacturer utilised this supply information by planning the timing of orders and reserving capacity from the subcontractors (SPPs). Some subcontractors knew the manufacturer's material requirements even better than the manufacturer itself. Thus, they proposed to the customer to place the orders (SVP) and usually the manufacturer agreed and placed them (SPP).

Example 6: order-related supply information and its utilisation. For manufacturers, the first potential risk for material availability is the order phase. For this reason, order-related supply information is essential supply information. One studied manufacturer had solved this as follows: first is order receipt check: if a subcontractor did not open an order in a system within $24 \mathrm{~h}$, an automatic exception notification was sent to the manufacturer (SVP); and second is order confirmation: if a subcontractor did not make an order confirmation during three days after the order, the system sent an automatic exception notification (SVP). In both cases, the manufacturer's purchaser contacted the subcontractor (SPP).

Example 7: post-order supply information and its utilisation. A manufacturer received from the logistics company post-order supply information about transport capacity reservations made by the subcontractors and the content of material loaded into the truck (SVPs). In this way, the manufacturer could compare whether the delivery corresponded to the order. If necessary, the manufacturer made proactive decisions, such as order the material from another subcontractor or reschedule their production (SPPs). When the supply information came from the capacity reservation phase, the manufacturer got information a week before the agreed delivery date. When the information came from the car-loading phase, the manufacturer was informed one or two days before the delivery date.

The information from the reservation phase was not as reliable and accurate as from the loading phase because subcontractors could have production problems after capacity reservation. Therefore, the booked capacity did not always match the material loaded into the car. On the other hand, subcontractors did not always specify the material to be transported precisely in the reservation phase, but only booked sufficient space from the car. Therefore, the information was also inaccurate at this stage. This example describes well how the reliability and accuracy of information depends on the timing of information shared.

Example 8: post-delivery date supply information and its utilisation. In the worst cases, a manufacturer received information about subcontractors' delivery delays only from its own 
IJOPM

39,4 material storage (SVP) when the material was needed. Actually, SVP was not located in the subcontractor's supply chain but in the manufacturer's process. In these kinds of situations, proactive decisions were not possible, and the manufacturer had to settle for reactive decisions, such as the rescheduling of production (SPP). Late deliveries by subcontractors were sometimes caused by the manufacturer because orders were delayed, but the delivery time was not changed. Thus, there were also problems with the timing of the demand information (DVP).

Example 9: synchronisation of demand-side flexibilities with supply uncertainties. Usually, the studied manufacturers resolved their subcontractors' delivery problems through their own flexibilities. This approach is similar to the subcontractor's flexibility example described earlier in example 4, but vice versa. The manufacturers had various predetermined flexibilities towards subcontractors' delivery problems. Above, examples 7 and 8 included demand-side flexibilities such as ordering material from other subcontractors and the rescheduling of production. The earlier the manufacturer received information about delivery problems, the less the disruption caused costs, because of the possibility to make anticipatory decisions to use the most suitable flexibility (SPP).

Example 10: integrated synchronisation model. There was no fully integrated synchronisation found in the manufacturer-subcontractor relationships studied. In general, discontinuities occurred when switching between different demand and supply information categories, but also within individual categories. However, the studied manufacturer and their subcontractors were more advanced in integrated synchronisation than others. The process started as supply-driven. As pre-order supply information, subcontractors offered the manufacturer visibility for their free capacity (SVP), which the manufacturer reflected in its own sales situation (SPP). When the manufacturer's own client's order became more likely, the manufacturer reserved from its subcontractors the capacity it needed (DVP) - especially if the capacity of the subcontractors seemed overloaded (SVP). When the manufacturer's client made an order, the manufacturer ordered the materials from its subcontractors (DVP, orderrelated demand information), resulting in subcontractors starting their production (DPP). Subsequently, the process continued with supply-driven synchronisation, where the subcontractors informed the manufacturer of delays in delivery (SVP, post-order supply information), which led to the use of the manufacturer's flexibilities (SPP).

\section{How new synchronisation tools help to create common understanding}

The new tools were experimented in the workshops with the same manufacturersubcontractor pairs and persons as the VOP-OPP at the beginning of the study. In the first phase, demand-supply chain synchronisation problems and development needs were identified with the new tools. In the second phase, the problems were prioritised, after which solutions were brainstormed in the final phase for the most important problems. As a result of the workshops, two manufacturers initiated development projects on demand-supply chain synchronisation with their subcontractors. This is a good example of how the new tools promoted inter-organisational learning, which has been found to lead to more innovative supply chain solutions (Zhu et al., 2018).

Based on reflection of the workshops, it became clear that the new tools helped to create a more in-depth understanding of practical synchronisation problems and development opportunities than the VOP-OPP. On the other hand, the tools were considered more complicated than the VOP-OPP. Clear and practical support material for the tools is needed if the tools are utilised without experts.

\section{Discussion}

The study's novel contribution is related to the modelling of demand-supply synchronisation in an uncertain environment as a comprehensive model (Figure 7). It includes information 


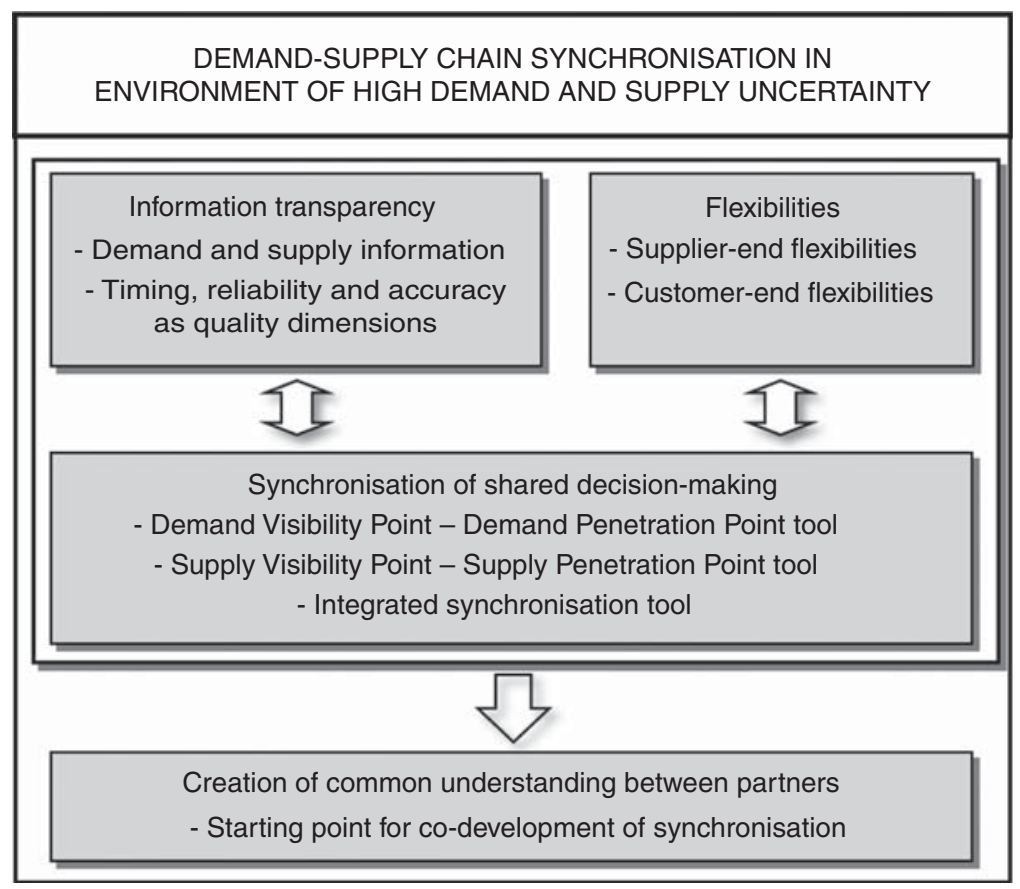

Demand-supply chain

synchronisation

587

Figure 7.

Comprehensive model for demand-supply chain synchronisation

transparency, the synchronisation of shared decision making, flexibilities and the creation of common understanding as main elements.

The comprehensive model promotes the co-innovation of demand-supply chain synchronisation between customer and supplier. The core idea behind synchronisation is to develop decision-making structures between companies, which is considered more challenging and useful than mere information sharing (Hietajärvi et al., 2009; Holweg et al., 2005).

The starting point for this is the creation of common understanding about problems, development ideas and the potential mutual benefits of synchronisation. The new model deals with synchronisation in a broader context than the VOP-OPP and its derivatives. This is in line with Rainbird's (2004) view concerning the limitations of the VOP-OPP model.

\section{Demand-supply chain coordination}

The study is positioned in demand-supply chain management, and more specifically within it in demand-supply chain coordination. Demand-supply chain coordination includes identifying interdependencies between partners and defining coordination mechanisms for managing them (Piplani and Fu, 2005; Simatupang et al., 2004). Coordination mechanisms help in improving the overall performance of the supply chain (Arshinder et al., 2011).

Interdependencies may occur between organisations, processes, functions and people (Whang, 1995). In this study, interdependencies occur between organisations (manufacturers and subcontractors) and between processes (demand and supply chains). The process dependencies were realised between information flows, material flows and shared decision making, which is in line with Lewis and Talalayevsky (2004), Simatupang and Sridharan (2005) and Kaipia (2007). 
IJOPM

39,4

588
The creation of common understanding (e.g. Jaatinen and Lavikka, 2008), synchronisation of shared decision-making (e.g. Simatupang et al., 2004), flexibilities (e.g. Kaipia, 2007) and information transparency (e.g. Goswami et al., 2013) were recognised as essential coordination mechanisms to synchronise demand-supply chains in uncertain circumstances.

The added value of the new tools compared to the VOP-OPP and its derivatives Three synchronisation tools are presented under the comprehensive model:

(1) the demand-oriented DVP-DPP model;

(2) The supply-orientedSVP-SPP model; and

(3) the integrated synchronisation connecting the DVP-DPP and SVP-SPP tools.

The DVP-DPP is close to the principles of the VOP-OPP, but differs from it in that it takes into account different kinds of demand information and its utilisation - not just orders and material allocation decisions. The SVP-SPP is the reverse version for the DVP-DPP. Unlike the VOP-OPP and its derivatives, the SVP-SPP also pays attention to supply information and its utilisation, which is in line with Fleischmann and Geier (2012) and Rainbird (2004).

The new tools include the timing, reliability and accuracy of information as the quality dimensions of information, which corresponds to the views of Baihaqi and Sohal (2013), Wiengarten et al. (2010), Gustavsson and Wänström (2009) and Kaipia (2007). The reliability and accuracy dimensions are missing from the VOP-OPP and its derivatives. The new tools also link demand and supply flexibilities to sychronisation, which is emphasised by Wochinger et al. (2013), Bauernhansl et al. (2012) and Kaipia and Holmström (2007).

In the DVP-DPP and SVP-SPP tools, the information shared is placed in four information categories in the timeline: pre-order, order-related, post-order and post-delivery date information. There may be several DVP or SVP points in the customer's demand chain or in the supplier's supply chain in each of these categories. Information shared from DVPs and SVPs penetrates different points in the supplier's supply chain (DPP) or in the customer's demand chain (SPP), where information is utilised in decision making. The VOPOPP and its derivatives do not have this kind of overall timeline perspective.

The integrated synchronisation tool connects the DVP-DPP and SVP-SPP together. In an ideal situation, synchronisation forms an unbroken pipeline between DVP-DPP and SVP-SPP, and between the four information categories in the timeline. This is in line with Rainbird's (2004) view on the need for a broad perspective to synchronisation missing from the VOP-OPP.

\section{Managerial implications}

Based on new synchronisation tool experiments, it became clear that these tools enable a deeper synchronisation analysis than the VOP-OPP tool. The new tools helped create a more in-depth understanding of practical synchronisation problems and development opportunities. However, the tools were considered more complicated than the VOP-OPP. This was not considered a bad thing, as long as the instructions for the tools were clear. Particularly, descriptions for how the tools have been utilised in practical synchronisation cases were requested. The main message from the practitioners was that more effort should be focussed on the creation of common understanding about collaborative issues, such as demand-supply chain synchronisation.

\section{Conclusions and need for further research}

The study presents a co-innovation toolbox and a comprehensive model for demand-supply chain synchronisation in a highly uncertain environment. Their goal is to help partners create common understanding of synchronisation problems and development needs for 
changing decision-making structures to improve the overall performance of the demandsupply chain. The toolbox includes three synchronisation tools: the DVP-DPP, SVP-SPP and integrated synchronisation. Both demand- and supply-driven synchronisation was taken into account. The timing, reliability and accuracy of information were recognised as essential information quality dimensions in highly uncertain circumstances.

The synchronisation model includes three coordination mechanisms for managing demand-supply chain dependencies: the synchronisation of shared decision-making, information sharing and flexibilities. The creation of a common understanding is the upper level mechanism for the other three mechanisms.

\section{Research limitations and further research}

The study proposes the new model and tools based on abductive reasoning and analytical generalisation in the specific demand-supply chain context. In further studies, the model and tools could be more deductively tested with multiple cases to strengthen the generalisation of the results.

The study concentrated on the restricted context of manufacturer-subcontractor relationships within the Finnish technology industry. Furthermore, the study focussed on a two-tier chain, ignoring the other parties. In addition, only subcontractors were studied as a supplier segment. The question of whether the new tools work in other contexts arises. Moreover, how could the tools be used in multi-tier chains or at network level, or in different industries and cultures, which all have their own characteristics?

The applicability of the VOP-OPP tool in different contexts indicates that the new tools may function in different environments. As with the VOP-OPP model, the general applicability of the new tools refers to the concepts, and not to the specific contents of the DVP, DPP, SVP and SPP, which have to be specified uniquely in different industries, and even in different demand-supply chains of the same industry.

In addition, it would be useful to study in more detail the inter-relationship of accuracy, reliability and timing of information in the synchronisation phenomenon. Finally, it would be interesting to extend the research from the common understanding of problems to the next phases of the co-innovation process: how co-innovation and co-development work could be intensified between the parties, and what effect would it have on improving the overall performance of the demand-supply chains?

\section{References}

Affonso, R., Marcotte, F. and Grabot, B. (2008), "Sales and operations planning: the supply chain pillar", Production Planning \& Control, Vol. 19 No. 2, pp. 132-141.

Alexander, E.R. (1995), How Organizations Act Together: Interorganizational Coordination in Theory and Practice, Gordon \& Breach, Philadelphia, PA.

Alvesson, M. and Sköldberg, K. (1994), Tolkning och Reflektion. Vetenskapsfilosofi och Kvalitativ Metod, Studentlitteratur, Lund.

Andreewsky, E. and Bourcier, D. (2000), "Abduction in language interpretation and law making", Kybernetes, Vol. 29 Nos 7/8, pp. 836-845.

Arshinder, K., Kanda, A. and Deshmukh, S.G. (2011), "A review on supply chain coordination: coordination mechanisms, managing uncertainty and research directions", in Choi, T.M. and Cheng, T. (Eds), Supply Chain Coordination under Uncertainty. International Handbooks on Information Systems, Springer, Berlin, Heidelberg, pp. 39-82.

Arun Kanda, A. and Deshmukh, S.G. (2008), "Supply chain coordination: perspectives, empirical studies and research directions", International Journal of Production Economics, Vol. 115 No. 2, pp. 316-335. 
IJOPM

39,4

Aslam, H., Blome, C., Roscoe, S. and Azhar, T.M. (2018), "Dynamic supply chain capabilities: how market sensing, supply chain agility and adaptability affect supply chain ambidexterity", International Journal of Operations \& Production Management, Vol. 38 No. 12, pp. 2266-2285.

Baihaqi, I. and Sohal, A. (2013), "The impact of information sharing in supply chains on organisational performance: an empirical study", Production Planning and Control, Vol. 24 Nos 8/9, pp. 743-758.

Barut, M., Faisst, W. and Kanet, J.J. (2002), "Measuring supply chain coupling: an information system perspective”, European Journal of Purchasing \& Supply Management, Vol. 8 No. 3, pp. 161-171.

Bauernhansl, T., Mandel, J. and Diermann, S. (2012), "Evaluating changeability corridors for sustainable business resilience", Proceedings of 45th CIRP CMS Conference on Manufacturing Systems, Athens, pp. 414-419.

Björk, K.-M. (2006), "Supply chain efficiency with some forest industry improvements", Dissertations Thesis, Åbo Akademi University, Painosalama Oy Turku.

Christopher, M. (1998), Logistics \& Supply Chain Management: Strategies for Reducing Costs and Improving Services, Pitman Publishing, London.

Collin, J. (2003), Selecting the Right Supply Chain for a Customer in Project Business - An Action Research Study in the Mobile Communications Infrastructure Industry, Helsinki University of Technology, Espoo.

Collin, J., Eloranta, E. and Holmström, J. (2009), "How to design the right supply chains for your customers", Supply Chain Management: An International Journal, Vol. 14 No. 6, pp. 411-417.

Danermark, B. (2001), Explaining Society: An Introduction to Critical Realism in the Social Sciences, Routledge, Florence, KY.

Datta, P. and Christopher, M. (2011), "Information sharing and coordination mechanisms for managing uncertainty in supply chains: a simulation study", International Journal of Production Research, Vol. 49 No. 3, pp. 765-803.

Dubois, A. and Gadde, L.-E. (2002), "Systematic combining: an abductive approach to case research", Journal of Business Research, Vol. 55 No. 7, pp. 553-560.

Dubois, A. and Gadde, L.-E. (2010), "Systematic combining - a decade later", Journal of Business Research, Vol. 67 No. 6, pp. 1277-1284.

Eltantawy, R., Paulraj, A., Giunipero, L., Naslund, D. and Thute, A. (2015), "Towards supply chain coordination and productivity in a three echelon supply chain: action research study", International Journal of Operations \& Production Management, Vol. 35 No. 6, pp. 895-924.

Fleischmann, B. and Geier, S. (2012), "Global available-to-promise”, in Stadtler, H., Fleichmann, B., Grunov, M., Meyer, H. and Sürie, C. (Eds), Advanced Planning in Supply Chains: Illustrating the Concepts Using an SAP AP 195. Case Study, Management for Professionals, Springer-Verlag, Berlin and Heidelberg, pp. 195-215.

Galasso, F., Mercé, C. and Grabot, B. (2009), "Decision support framework for supply chain planning with flexible demand", International Journal of Production Research, Vol. 47 No. 2, pp. 455-478.

Godsell, J., Masi, D., Karatzas, A. and Brady, T.M. (2018), "Using project demand profiling to improve the effectiveness and efficiency of infrastructure projects", International Journal of Operations \& Production Management, Vol. 38 No. 6, pp. 1422-1442.

Goswami, S., Engel, T. and Krcmar, H. (2013), "A comparative analysis of information visibility in two supply chain management information systems", Journal of Enterprise Information Management, Vol. 26 No. 3, pp. 276-294.

Gustavsson, M. and Wänström, C. (2009), "Assessing information quality in manufacturing planning and control processes”, International Journal of Quality \& Reliability Management, Vol. 26 No. 4, pp. 325-340.

Hietajärvi, A.-M., Salmela, E., Happonen, A. and Hemilä, J. (2009), "The present state of the demand-supply chains' synchronization in the Finnish metal and machinery industry", Proceedings of LRN, Cardiff, 9-11 September. 
Hilletofth, P. (2011), "Demand-supply chain management: industrial survival recipe for new decade", Demand-supply Industrial Management and Data Systems, Vol. 111 No. 2, pp. 184-211.

Hilletofth, P. and Lättilä, L. (2012), "Framework for demand chain and supply chain coordination", synchronisation International Journal of Services Sciences, Vol. 4 Nos 3/4, pp. 240-256.

Hirvonen, V. (2006), "Capturing advance demand information from project delivery networks for demand supply planning", Helsinki University of Technology, Report 2006/1, Helsinki.

Hoekstra, S. and Romme, J. (1992), Integrated Logistics Structures: Developing Customer Oriented Goods Flow, McGraw-Hill, London.

Holmström, J., Hoover, W.E., Eloranta, E. and Vasara, A. (1999), "Using value reengineering to implement breakthrough solutions for customers", International Journal of Logistics Management, Vol. 10 No. 2, pp. 1-12.

Holmström, J., Ala-Risku, T., Auramo, J., Collin, J., Eloranta, E. and Salminen, A. (2010), "Demand supply chain representation: a tool for economic organizing of industrial services", Journal of Manufacturing Technology Management, Vol. 21 No. 3, pp. 376-387.

Holweg, M., Disney, S., Holmström, J. and Småros, J. (2005), “Supply chain collaboration: making sense of the strategy continuum”, European Management Journal, Vol. 23 No. 2, pp. 170-181.

Hoover, W.E., Eloranta, E., Holmström, J. and Huttunen, K. (2001), Managing the Demand-Supply Chain, John Wiley \& Sons, Inc, New York, NY.

Hopp, W.J. and Sperman, M.L. (2008), Factory Physics, 3rd ed., Waveland Press, Long Grove, IL.

Huiskonen, J. (2004), "Supply chain integration: studies on linking customer responsiveness and operational efficiency in logistics policy planning", dissertation thesis, Lappeenranta University of technology, Digipaino 2004, Lappeenranta.

Jaatinen, M. and Lavikka, R. (2008), "Common understanding as a basis for coordination", Corporate Communications: An International Journal, Vol. 13 No. 2, pp. 147-167.

Kafi, F. and Kafi, M. (2016), "Information quality in supply chain software", Handbook of Research on Global Supply Chain Management, IGI Global, pp. 105-126.

Kaipia, R. (2007), "Supply chain coordination - studies on planning and information sharing mechanisms", Doctoral Dissertation Series 2007/2, Helsinki University of Technology, Laboratory of Industrial Management, Espoo.

Kaipia, R. (2009), "Coordinating material and information flows with supply chain planning", The International Journal of Logistics Management, Vol. 20 No. 1, pp. 144-162.

Kaipia, R. and Hartiala, H. (2006), "Information-sharing in supply chains: five proposals on how to proceed", The International Journal of Logistics Management, Vol. 17 No. 3, pp. 377-393.

Kaipia, R. and Holmström, J. (2007), "Selecting the right planning approach for a product", Supply Chain Management: An International Journal, Vol. 12 No. 1, pp. 3-13.

Kaipia, R., Holmström, J. and Hellström, M. (2007), "Measuring the benefit of changing the value offering in grocery supply chains", Production Planning \& Control, Vol. 18 No. 2, pp. 131-141.

Ketokivi, M. and Mantere, S. (2010), "Two strategies for inductive reasoning in organizational research", Academy of Management Review, Vol. 35 No. 2, pp. 315-333.

Kovács, G. and Spens, K.M. (2005), “Abductive reasoning in logistics research”, International Journal of Physical Distribution \& Logistics Management, Vol. 35 No. 2, pp. 132-144.

Langabeer, J. and Rose, J. (2001), Creating Demand Driven Supply Chains, Chandos Publishing, Oxford.

Lavikka, R. (2015), "Coordination for shared knowledge creation in the development and management of inter-organizational business processes", Aalto University publication series Doctoral dissertations 95/2015, Helsinki.

Lewis, I. and Talalayevsky, A. (2004), "Improving the interorganisational supply through optimization of information flows", The Journal of Enterprise Information Management, Vol. 17 No. 3, pp. 229-237. 
IJOPM

39,4

Li, G., Lin, Y., Wang, S. and Yan, H. (2006), "Enhancing agility by timely sharing of supply information", Supply Chain Management: An International Journal, Vol. 11 No. 5, pp. 425-435.

Li, X. and Wang, Q. (2007), "Coordination mechanisms of supply chain systems”, European Journal of Operational Research, Vol. 179 No. 1, pp. 1-16.

Moon, S.-A. and Kim, D.-J. (2005), "Systems thinking ability for supply chain management", Supply Chain Management: An International Journal, Vol. 10 No. 5, pp. 394-401.

Pagell, M. and Krause, M. (2004), "Re-exploring the relationship between flexibility and the external environment", Journal of Operations Management, Vol. 21 No. 6, pp. 629-649.

Piplani, R. and Fu, Y. (2005), "A coordination framework for supply chain inventory alignment", Journal of Manufacturing Technology Management, Vol. 16 No. 6, pp. 598-614.

Rainbird, M. (2004), "Demand and supply chains: the value catalyst", International Journal of Physical Distribution \& Logistics Management, Vol. 34 No. 3, pp. 230-250.

Rojas, S.J.P. and Frein, Y. (2008), "Coordination and demand uncertainty in supply chains", Production Planning \& Control, Vol. 19 No. 7, pp. 712-721.

Salmela, E. and Happonen, A. (2008), "Demand and supply chain management in small advertising agency", Proceedings of EurOMAO8 15th International Annual EurOMA Conference, Groningen.

Salmela, E. and Happonen, A. (2010), Kilpailuetua päätöksenteon synkronoinnilla?, Lappeenrannan teknillinen yliopisto, Teknistaloudellinen tiedekunta, Tuotantotalouden osasto, Tutkimusraportti 220, Digipaino.

Salmela, E., Happonen, A. and Huiskonen, J. (2012), "New concepts for demand-supply chain synchronization”, International Journal of Manufacturing Research, Vol. 7 No. 2, pp. 148-164.

Sawhney, R. (2006), "Interplay between uncertainty and flexibility across the value chain: towards a transformation model of manufacturing flexibility", Journal of Operations Management, Vol. 24 No. 5, pp. 476-493.

Scholz, R.W. and Tietje, O. (2002), Embedded Case Study Methods: Integrating Quantitative and Qualitative Knowledge, Sage Publications Inc, London.

Simatupang, T.M. and Sridharan, R. (2005), "Supply chain discontent”, Business Process Management Journal, Vol. 11 No. 4, pp. 349-369.

Simatupang, T.M. and Sridharan, R. (2008), "Design for supply chain collaboration”, Business Process Management Journal, Vol. 14 No. 3, pp. 401-418.

Simatupang, T.M., Sandroto, I.V. and Hari Lubis, S.B. (2004), "A coordination analysis of the creative design process", Business Process Management Journal, Vol. 10 No. 4, pp. 430-444.

Soroor, J., Tarokh, M.J. and Shemshadi, A. (2009), "Theoretical and practical study of supply chain coordination”, Journal of Business \& Industrial Marketing, Vol. 24 No. 2, pp. 131-142.

Walker, W.E., Harremoes, P., Rotmans, J., Vander Sluijs, J.P., Van Asselt, M.B.A., Janssen, P. and Krauss, K.V. (2003), "Defining uncertainty: a conceptual basis for uncertainty management in model based decision support”, Integrated Assessment, Vol. 4 No. 1, pp. 5-17.

Walters, D. (2006), "Demand chain effectiveness - supply chain efficiencies: a role for enterprise information management", Journal of Enterprise Information Management, Vol. 19 No. 3, pp. 246-261.

Weick, K.E. (1979), The Social Psychology of Organizing, Random House, New York, NY.

Whang, S. (1995), "Coordination in operations: a taxonomy", Journal of Operations Management, Vol. 12 Nos 3/4, pp. 413-422.

Wiengarten, F., Humphreys, P., Cao, G., Fynes, B. and McKittrick, A. (2010), "Collaborative supply chain practices and performance: exploring the key role of information quality", Supply Chain Management: An International Journal, Vol. 15 No. 6, pp. 463-473.

Wochinger, T., Zwißler, F. and Westkämper, E. (2013), "A reference model for a synchronized and dynamic alignment of the order fulfillment process", in Azevedo, A. (Ed.), Advances in Sustainable and Competitive Manufacturing Systems, Lecture Notes in Mechanical Engineering, Springer International Publishing, New York City, pp. 787-798. 
Yin, R. (2003), Case Study Research: Design and Methods, 3rd ed., Sage Publications, London.

Yin, R.K. (2010), Qualitative Research from Start to Finish, The Guilford Press, New York, NY.

Demand-supply chain

Yuan, X., Zhang, L. and Ashayeri, J. (2013), "Hybrid positioning mode of VOP and OPP in demandsupply chains", in Qi, E., Shen, J. and Dou, R. (Eds), Proceedings of the 19th International synchronisation Conference on Industrial Engineering and Management Innovation (IEMI2012) Proceedings, Springer, Berlin, Heidelberg, pp. 460-465.

Zeng, Z. and Pathak, K. (2003), "Achieving information integration in supply chain management through B2B e-hubs: concepts and analyses", Industrial Management and Data Systems, Vol. 103 No. 9, pp. 657-665.

Zhu, Q., Krikke, H. and Caniëls, M.C.J. (2018), "Supply chain integration: value creation through managing inter-organizational learning", International Journal of Operations \& Production Management, Vol. 38 No. 1, pp. 211-229.

\title{
Further reading
}

Barrat, M. and Oke, A. (2007), "Antecedents of supply chain visibility in retail supply chains: a resourcebased theory perspective”, Journal of Operations Management, Vol. 25 No. 6, pp. 1217-1233.

Wikner, J. and Rudberg, M. (2005), "Introducing a customer order decoupling zone in logistics decision making”, International Journal of Logistics, Vol. 8 No. 3, pp. 211-224.

\begin{abstract}
About the authors
Dr Erno Salmela is Post-Doctoral Researcher in Lappeenranta University of Technology, Finland. His research focusses on supply chain development and innovation management. He has more than 20 years' experience in university-industry research projects and collaboration.

Professor Janne Huiskonen holds the professorship of Supply Chain Management in Lappeenranta University of Technology (LUT), Finland. His research focusses on sustainable business models and operations management in supply chains, networks and service systems. He has published over 40 articles in scientific conferences and journals. He is Head of the Department of Industrial Engineering and Management at LUT. Professor Janne Huiskonen is the corresponding author and can be contacted at: Janne.Huiskonen@lut.fi
\end{abstract}

For instructions on how to order reprints of this article, please visit our website: 